\title{
Entre percursos, fontes e sujeitos: pesquisa em educação e uso da história oral
}

\author{
Rosimar Serena Siqueira Esquinsani \\ Universidade de Passo Fundo
}

\section{Resumo}

Este artigo tece considerações acerca da história oral, apresentando reflexões sobre a posição do sujeito como colaborador em pesquisas e alguns desdobramentos dessa posição singular. Como aporte ilustrativo, parte-se de um estudo já concluído, o qual remete às disputas políticas e religiosas que precederam a aprovação da Lei de Diretrizes e Bases da Educação Nacional n ${ }^{0} 4.024$, de 1961. Na construção do estudo, a história oral foi utilizada como metodologia comprometida com o resgate da informação e da própria constituição dos sujeitos colaboradores, a partir de seu lugar social e de suas relações e reações diante do fato narrado. Centrando as reflexões em torno da posição do sujeito como fonte de pesquisa - sem discutir ou aprofundar o episódio mencionado -, o artigo considera que reconstruir a memória daquele período também significou revigorar caricaturas, contradições e conflitos presentes nas interpretações particulares de cada um dos colaboradores. São apresentados, ainda, excertos das narrativas utilizadas na pesquisa empírica, os quais demonstram que a descrição dos fatos pelos sujeitos partícipes da pesquisa não perdeu seu estatuto de apreensão pessoal, constituindo-se como uma representação do grupo social a que tais sujeitos acreditavam pertencer. Como conclusão, sugere-se que a apreensão da memória é sempre uma tarefa de referência: naquele momento e sob aquelas condições, a narrativa possibilitou aquelas nuanças.

\section{Palavras-chave}

História oral - Pesquisa em educação - Sujeitos - História da educação.

\footnotetext{
Correspondência:

Rosimar Serena Siqueira Esquinsani

Universidade de Passo Fundo

Programa de Pós-Graduação

em Educação

BR 285, Cx. Postal 611

99052-900 - Passo Fundo/RS

rosimaresquinsani@upf.br
} 


\title{
Between trajectories, sources and subjects: research in education and the use of oral history
}

Rosimar Serena Siqueira Esquinsani

University of Passo Fundo

\begin{abstract}
This article is a commentary on oral history, presenting reflections about the collaborative position of the subject in researches, and some of the consequences of this singular position. As an illustrative contribution the article starts from a study previously carried out, which refers to the political and religious disputes that preceded the sanctioning of the 4024 Law of National Education Bases and Guidelines of 1961. In constructing this study, oral history was used as a methodology dedicated to recovering information and the very constitution of the collaborative subjects based on their social locus and on the relations and reactions to the fact narrated. Centering the reflections on the position of the subject as a source for the research - without discussing or going deeper into the episode mentioned -, the article considers that reconstructing the memory of that period also meant to rekindle caricatures, contradictions and conflicts present in the particular interpretations of each one of the collaborators. The text also presents excerpts from narratives used in the empirical research, which demonstrate that the description of the facts by the participating subjects did not lose its statute of a personal perception, constituting a representation of the social group to which the subjects believed to belong. In conclusion, the article suggests that the capturing of memory is always a referential task: at that moment and under those conditions the narrative made those nuances possible.
\end{abstract}

\section{Keywords}

Oral history - Research in education - Subjects - History of education.

Contact:

Rosimar Serena Siqueira Esquinsani

Universidade de Passo Fundo

Programa de Pós-Graduação em Educação

BR 285, Cx. Postal 611

99052-900 - Passo Fundo/RS

rosimaresquinsani@upf.br 
[...] um acontecimento vivido é finito, ou pelo menos encerrado na esfera do vivido, ao passo que o acontecimento lembrado é sem limites, porque é apenas uma chave para tudo o que veio antes e depois. Walter Benjamin

Este texto apresenta considerações acerca da utilização da história oral em pesquisas na área da educação. Delimita argumentos exclusivamente em torno da posição do sujeito que se dispõe a partilhar suas lembranças em colaboração com o sujeito que pesquisa, pois não tem como foco reflexões sobre a metodologia ou o estatuto epistemológico de tal caminho investigativo. Assim, traz como objetivo precípuo refletir sobre a posição do sujeito colaborador de uma pesquisa com história oral.

Os caminhos da pesquisa desenham-se em face do objeto de interesse e das possibilidades concretas (fontes) de aproximação desse objeto. Tais percursos delineiam-se, ainda, em razão das escolhas do pesquisador diante das maneiras de aproximação do objeto de interesse, da plausibilidade, da logística e da pertinência do estudo, por meio de uma ou outra fonte, ou, ainda, do diálogo entre diferentes fontes. Dentre as possibilidades de aproximação do objeto, figura o trabalho com fontes orais.

Na expectativa de problematizar e bem colocar as questões atinentes à área, há uma sólida produção acadêmica sobre os passos metodológicos a serem utilizados para se retirar o melhor das fontes orais (THOMPSON, 1992; MEIHY, 2005; FERREIRA; AMADO, 2001; DELGADO, 2006, MEIHY; HOLANDA, 2007; MONTENEGRO, 2010; entre outros). Os autores citados - dentre muitos outros - já elaboraram e publicizaram estudos sobre a história oral como método de pesquisa, e, por essa razão, o texto em tela coloca-se em uma direção singular em relação ao assunto, procurando discutir a posição daquele que tem suas memórias vasculhadas pelo pesquisador: o sujeito constituído como fonte da pesquisa.

Para dar consistência e argumentos à proposta de discussão, o texto faz referência à expe- riência e aos elementos empíricos obtidos a partir de uma pesquisa já concluída sobre história da educação (ESQUINSANI, 2002). A pesquisa anterior, sobre a qual houve um novo olhar procurando arrestar a problemática do sujeito de investigação, foi desenvolvida segundo uma abordagem qualitativa a partir de fontes orais e documentais, conduzida com o objetivo de examinar a repercussão das disputas políticas que remetem ao final da década de 1950 e que precederam a aprovação da Lei de Diretrizes e Bases da Educação Nacional $\mathrm{n}^{\circ}$ 4.024, de 1961, disputas estas protagonizadas pelo educador baiano Anísio Spínola Teixeira (1900-1971) e pelo arcebispo gaúcho Alfredo Vicente Scherer (1903-1996).

Em 1948, o Ministério da Educação e Cultura apresentou o anteprojeto de Clemente Mariani, proposta daquela que viria a ser a primeira Lei de Diretrizes e Bases da Educação Nacional, inaugurando uma nova etapa nas históricas discussões entre os defensores da escola pública e os contrários à maior intervenção do Estado no campo educacional, estes sob forte liderança da Igreja Católica. Nesse cenário já estava posicionado o educador Anísio Teixeira, identificado pela Igreja Católica - em razão de seu prestígio intelectual e do alcance de sua obra - como elemento a ser combatido, pois advogava em favor da escola pública, considerada por ele a única instituição verdadeiramente democrática.

Os ânimos exaltaram-se no final da década de 1950, quando, no dia 23 de fevereiro de 1958, Dom Vicente Scherer fez um discurso por ocasião de seu décimo primeiro aniversário de sagração episcopal, que consistiu em um verdadeiro manifesto em defesa das concepções educacionais da Igreja Católica, além de representar um ataque aberto a Anísio Teixeira. Em março do mesmo ano, Dom Vicente lançou com seus pares o Memorial dos bispos gaúchos ao Presidente da República sobre a Escola Pública Única (SCHERER, 1958), promovendo novo ataque a Anísio Teixeira.

Naquele contexto, a Igreja Católica partiu para o enfrentamento político, pressionando diretamente o Ministro da Educação e o governo 
federal; articulando-se com parte do Parlamento; buscando mobilizar a opinião pública acerca da legitimidade de suas posições em defesa da escola privada; lançando mão do argumento pautado na liberdade da família em escolher a educação para seus filhos; e evocando o elemento dogmático de um povo marcadamente católico que, supostamente, por livre-iniciativa, não confiaria a educação de seus filhos a uma escola estatal e laica. Os defensores da escola pública reagiram na mesma proporção, o que gerou manifestações de grupos organizados em torno das duas posições e levou a imprensa à discussão sobre o destino da educação no país, discussão permeada por polêmicas embaladas por um conteúdo fortemente ideológico.

No âmbito da pesquisa anterior - que serve de gênese para as reflexões aqui expressas -, a fim de investigar a repercussão de tal debate, bem como a relevância daquele momento para a história da educação, assumiram forma singular os relatos de colaboradores que, tendo vivido o período em questão, partilharam suas memórias por meio de reconstruções narrativas sobre o episódio.

De fato, pela amplitude e disponibilidade das fontes documentais acerca do recorte pretendido, os depoimentos orais não seriam necessariamente definidores do posicionamento ou dos caminhos da pesquisa. Naquele caso, os depoimentos orais indicavam, especificamente, duas finalidades: a) incrementar a análise dos documentos, possibilitando uma triangulação de fontes e, por conseguinte, a produção de um relato diferenciado sobre o episódio; b) trazer vida para dentro da narrativa, no ensaio de mostrar como um episódio polêmico é capaz de manter aquecida a memória, deixando-a aguerrida e posicionada diante da retomada dos fatos para o registro da pesquisa.

Para tanto, a história oral foi utilizada como metodologia comprometida com o resgate da informação, mas também com a própria constituição do sujeito que presta a informação, com seu lugar social e com as relações e reações diante do fato relatado. Tecnicamente, foram realizadas entrevistas abertas e individuais com os colaboradores, as quais, depois de transcritas, passaram pela revisão dos entrevistados e, após os ajustes solicitados, foram incorporadas à pesquisa com a devida concessão de uso.

Concluída aquela pesquisa, houve uma concentração de esforços nos argumentos em torno da posição do sujeito como fonte de investigação, sem a intenção de discutir ou aprofundar o episódio descrito. Inauguraram-se, então, análises sobre o sentido da memória para os sujeitos colaboradores, levando em consideração que

a história oral é uma história construída em torno de pessoas. Ela lança a vida para dentro da própria história e isso alarga seu campo de ação. Admite heróis não só dentre os líderes, mas dentre a maioria desconhecida do povo. Estimula professores e alunos a serem companheiros de trabalho. Traz a história para dentro da comunidade e extrai a história de dentro da comunidade. (THOMPSON, 1992, p. 44)

Essa pessoalidade em torno da qual é construída a história oral concorre para que as entrevistas configurem-se como documentos parciais que contêm uma versão do passado, um olhar perspectivado e particular do sujeito entrevistado. Tal parcialidade não é diferente do documento físico; entretanto, pelas subjetividades em jogo no momento de organizar as ideias da pesquisa, as fontes orais merecem a reflexão sobre questões de outra ordem, como a condição dos sujeitos que dividem (e, portanto, constroem e reconstroem) suas memórias em relatos que atendem à demanda do pesquisador, e não necessariamente ao livre-trâmite da memória.

Deve-se frisar que esta é a intenção primordial deste texto: discutir a posição singular do sujeito narrador e das possíveis implicações do mesmo nos processos de pesquisa em história da educação. Trata-se, pois, de um novo olhar sobre entrevistas produzidas para um momento particular da história da educação; no caso em tela, elas foram anali- 
sadas a partir das particularidades da relação entre memória individual e memória social dos sujeitos de investigação.

\section{Subjetividade e memória: os sujeitos como fonte da pesquisa}

Para a escolha dos colaboradores, foi realizado um levantamento inicial dos potenciais coadjuvantes do episódio, sendo considerados o grau de envolvimento com o evento e o lugar social ocupado, além de questões logísticas e de acesso aos sujeitos. Ao final de um levantamento preliminar, restaram quatro sujeitos possíveis colaboradores, cujos nomes surgiram após consolidada a pesquisa em fontes documentais - jornais, anais da assembleia legislativa, periódicos -, as quais apontaram para a participação ativa dos quatro entrevistados no debate ocorrido.

Assim, os colaboradores, presentes e quinhoeiros dos fatos pelos lugares sociais que ocuparam, foram situados como fontes da pesquisa e consultados acerca da partilha de suas lembranças sobre um evento de datação longínqua, mas de memória ainda viva, em uma duplicidade questionadora, uma vez que as memórias são dos sujeitos que as evocam e não dos fatos lembrados (apesar de serem sobre os fatos lembrados).

No caso desses senhores cujas longas e ricas trajetórias e relatos serviram de fonte, tornou-se imperioso entender que resgatar a memória de um período também significava reconstruir e produzir representações, subjetividades, contradições e conflitos, bem como as mais diversas interpretações e pontos de vista acerca dos fatos do passado.

Nessa direção, a partir da epígrafe de Walter Benjamim aqui inserida, é possível afirmar que a memória possui o condão de tornar o acontecimento imortal. Mas o status de imortalidade só é atingido após a delação do acontecimento por meio das composições e dos relatos advindos da memória (e das artimanhas desta). Assim, a memória é a chave que permite ao pesquisador apropriar-se do acontecimento pela via interpretativa de quem o viveu e que, ao narrar, reconstrói o vivido à sua maneira e torna o fato imortal.

Para a produção da pesquisa, a história oral apresentou-se como uma opção metodológica que possibilitou o confronto de fontes, a mescla de perspectivas e a mistura de olhares. Ocorre que esse processo é sempre permeado pela troca de impressões entre dois sujeitos distintos: o pesquisador e suas intenções de pesquisa, e o sujeito que narra suas lembranças, com as múltiplas perspectivas da memória.

Há, nesse ponto, um paradoxo entre o tangível e o intangível. 0 pesquisador é alguém que não viveu a história (episódio, fato etc.), mas que deseja atribuir a esta, por meio dos mecanismos da pesquisa científica, um valor tangível do ponto de vista acadêmico. Para tanto, lança mão de sujeitos narradores que viveram os fatos e que se tornam, no contexto da pesquisa, sujeitos de investigação. Porém, diferentemente do pesquisador, os sujeitos narradores debruçam-se sobre suas próprias sombras ao recordar elementos que são, do ponto de vista pessoal, intangíveis.

Nas palavras do sociólogo francês Maurice Halbwachs (2004),

a lembrança é em larga medida uma reconstrução do passado com a ajuda de dados emprestados do presente, e além disso, preparada por outras reconstruções feitas em épocas anteriores e de onde a imagem de outrora manifestou-se já bem alterada. (p. 75-6)

0 uso da história oral traz à baila, portanto, duas subjetividades - a do pesquisador e a do narrador -, bem como dois pontos de vista sobre a mesma história ou fato narrado: um circunstanciado pela teoria, outro permeado pela vivência empírica - com todos os seus tons, encadeamentos e sentimentos -, já embaralhada pelas interpretações particulares do fato. 
Os entrevistados falaram com aparente consciência do lugar que ocupavam na narrativa, bem como das eventuais faces e compromissos que representariam perante determinado grupo social.

Os quatro colaboradores (que serão nominados de 01, 02, 03 e 04), ao elaborarem seus relatos, dividiram-se entre favoráveis e contrários a Anísio Teixeira, personalizando as lembranças acerca do episódio e relatando-o de acordo com seus posicionamentos. Em nenhum momento eles discutiram o mérito da questão sobre o financiamento da educação expressa no debate narrado, mas centraram o foco nas ideologias e nos personagens, emitindo juízo de valor com base em suas referências e lembranças, ora sobre Dom Vicente, ora sobre Anísio Teixeira.

Dois sujeitos colaboradores manifestaram-se contrários a Anísio e aos princípios que o educador baiano representava (ainda que estivessem narrando um episódio ocorrido quatro décadas antes). Eles mantiveram-se fiéis à defesa do discurso de Dom Vicente e traduziram essa fidelidade em sutis ataques à figura de Anísio, mesmo post mortem. Outro colaborador manifestou-se favorável a Anísio Teixeira, moldando sua narrativa de forma a preservá-lo e defendendo enfaticamente o projeto de escolarização pública. Um dos sujeitos entrevistados (sujeito 01), porém, apresentou-se de maneira emblemática: permaneceu, ao longo dos relatos, dividido entre a razão (que o levava a concordar com o educador baiano e suas ideias) e o lugar social que ocupava, pois, durante a entrevista, lembrava constantemente sua sólida formação católica e - ao que parece, em virtude desta - manifestava a impossibilidade de assumir, mesmo em suas lembranças, posição contrária ao discurso de Dom Vicente.

A memória individual, construída a partir das referências e lembranças próprias do grupo, refere-se, portanto, a 'um ponto de vista sobre a memória coletiva'. Olhar este, que deve sempre ser analisado considerando-se o lugar ocupado pelo sujeito no interior do grupo e das relações mantidas com outros meios. (HALBWACHS, 2004, p. 55)

Com base nas referências de grupo, como esse sujeito poderia se colocar em rota de colisão com sua própria identidade católica? Como poderia se referir positivamente a Anísio Teixeira tendo vivenciado um contexto aguerrido de ataques ao educador baiano, desferidos justamente por representantes católicos? Como seria capaz de espaçar ideologia, projeto educacional e dogma em um relato sobre o episódio?

Em geral, o sujeito colaborador, ao ser entrevistado e instado a relatar um fato, executará essa tarefa de acordo com seu olhar particular, com seu modo de ver e sentir o fato que se condiciona a relatar. As omissões e os recortes são de sua responsabilidade e desdobram-se a partir de apreensões individuais (próprias, pessoais, subjetivas) ou sociais (representação da classe ou grupo a que o indivíduo acredita estar vinculado).

A memória é recoberta por associações e vínculos de pertença que a envolvem, não permitindo que seja chamada ao presente sem que a consciência da identidade social também se faça presente nos relatos. Assim, um sujeito colaborador não esquece seu lugar social e preserva-o, sobretudo, por meio dos rituais da narrativa. Não se trabalha a memória em um vazio de sentido, mas em um quadro de referências mais ou menos rígido, no qual

percorrer a trilha do relato construído é visitar um labirinto de muitas voltas, de muitas dobras que, ao se desfazerem, aproximam passado e presente, distanciam passado e presente, numa tensão de quem conhece o poder das palavras, de quem sabe quanto elas significam: um perigoso campo minado. (MONTENEGRO, 2010, p. 43)

No exame das entrevistas, fica evidente a dicotomia entre o que o sujeito colaborador 
acredita e o que ele deve, conscientemente, informar no contexto da pesquisa. Nessa perspectiva, cumpre problematizar uma aparente contradição: por que defender intransigentemente um dos lados, por exemplo, ou proteger/esconder eventuais mazelas e tentar conduzir as conclusões da pesquisa mesmo tanto tempo depois?

Halbwachs (2004) assevera que tal paradoxo é fruto da negociação particular entre memória pessoal e memória social, ambas devidamente caracterizadas no excerto que segue:

uma interior ou interna, a outra exterior; ou então, uma memória pessoal, a outra memória social. Diríamos mais exatamente ainda: memória autobiográfica e memória histórica. A primeira se apoiaria na segunda, pois toda história de nossa vida faz parte da história em geral. Mas a segunda seria, naturalmente, bem mais ampla do que a primeira. Por outra parte, ela não nos representaria o passado senão sob uma forma resumida e esquemática, enquanto a memória de nossa vida nos apresentaria um quadro bem mais contínuo e mais denso. (p. 59)

Ao discorrer sobre o episódio pesquisado, os sujeitos colaboradores traziam a referência dessas duas memórias. Por mais densa e rica, a memória pessoal fazia-se presente em todas as ocasiões, ora justificando as narrativas da memória social, ora tentando seduzir e desviar o caminho da pesquisa para o ponto de vista pessoal sobre o assunto.

Isso ocorre porque 0 ato de lembrar envolve e revolve tanto a memória coletiva quanto a memória individual em um plasma de difícil definição. Ainda que a memória esteja ancorada nas percepções individuais, ela remete a uma forma determinada de assimilar tais percepções: o grupo de pertencimento. De acordo com Halbwachs (2004),

cada memória individual é um ponto de vista sobre a memória coletiva, [...] este ponto muda conforme o lugar que ali ocupo, e [...] este lugar mesmo muda segundo as relações que mantenho com os outros meios. (p. 55)

As memórias ancoradas no sentimento de pertencimento a determinado grupo social não permitiram que antigas convenções fossem quebradas, sobretudo porque rompê-las significaria aceitar a falibilidade dos argumentos utilizados no evento em foco, tanto de um lado quanto de outro da contenda. Abjurar o passado seria como trair a si mesmo. Assumir eventuais falhas em seus argumentos e assumir outra posição em outro contexto seria uma traição para com os eventos relatados e os sentimentos envolvidos.

Os fatos narrados não são como as fontes documentais, que ficam dispostas à espera do pesquisador, mas são fragmentos de memória, retalhos descontínuos, decompostos, que, por meio da narrativa, ganham forma e consistência. Eles são remontados e socializados com o pesquisador para, depois, tornarem-se fragmentos novamente.

Em razão do trabalho de elaboração, resultante da relação que se estabelece entre as memórias (passado) e a percepção de algo (presente), as marcas que se constituem como memórias devem ser compreendidas como registros híbridos. (MONTENEGRO, 2010, p. 40)

Nessa direção,

um acontecimento ou uma situação vivida pelo entrevistado não pode ser transmitido a outrem sem que seja narrado. Isto significa que ele se constitui (no sentido de tornar-se algo) no momento mesmo da entrevista. (ALBERTI, 2004, p. 77)

Trata-se de um processo de composição e decomposição da memória; de um jogo dialético de lembranças, narrativas e esquecimentos que, ao se tornarem palatáveis para o pesquisador, 
assumem a forma que a memória e a narrativa do momento permitem.

\section{Os excertos das entrevistas e a posição singular do sujeito colaborador}

Às interpretações particulares que conduziram o relato dos sujeitos colaboradores da pesquisa subjaz certo tom de desconforto diante das lembranças do acontecimento, o que evolui na (nem sempre tão) sutil forma de estratégias de narrativa que visam alterar o foco da pesquisa, como as justificativas para ações e personagens. Assim, todas as narrativas foram tecidas sob a marca de sentimentos que atuaram como censores ao que seria reconstruído no relato, condicionando palavras e sentenças, influenciando no emprego de adjetivos e, em alguns momentos, permitindo até mesmo o uso de certo sarcasmo.

O sentimento de desconforto - que traz acoplada a necessidade de constantes justificativas a atos e pronunciamentos - fica expresso, com frequência, nos recursos narrativos utilizados pelos defensores de Dom Vicente. Há a tentativa constante e clara de relativização sobre qualquer característica que possa envolver alguma imagem pejorativa da figura do então arcebispo metropolitano de Porto Alegre, como nos excertos a seguir, extraídos do diálogo entre dois sujeitos colaboradores: "Ora, o Dom Vicente era de um caráter um pouco especial, mas..." (sujeito 02); "Um caráter bastante rígido!" (sujeito 03); "Rígido. Um pouco germânico. Mas foi um bom arcebispo!" (sujeito 02).

Todas as eventuais ações de Dom Vicente eram antecipadamente justificadas por seus defensores, com base em uma (tácita) lei de compensação: ele pode até ter dito isso, mas era um homem tão bom... Tal lei de compensação antecipava-se a cada fala, como se o sujeito narrador estivesse comprometido em desculpar qualquer ato de Dom Vicente, até mesmo pela supervalorização das qualidades, ainda que não solicitadas no diálogo: "Dom Vicente... se fez sacerdote e cultivou a vida de sacerdote, vida de humildade" (sujeito 01).

0 sujeito colaborador não permite que sejam traídos antigos pactos em relação ao lugar social que ocupava por ocasião dos fatos e que continua representando no presente: uma vez católico, sempre católico.

Se certo membro do grupo vier a fazer parte ao mesmo tempo de um outro grupo, se os pensamentos que ele tem de um e do outro se encontram de repente em seu espírito... teoricamente, só ele perceberá esse contraste. (HALBWACHS, 2004, p. 49)

Esse é o caso singular do sujeito 01 . Mesmo apresentando um perfil típico dos apoiadores de Anísio, ou seja, considerado culto, admirador dos ideais anisianos de democracia e liberdade, autoproclamado defensor da escola pública e de novas metodologias para o ensino etc., ele era católico (!), e esse pseudoparadoxo acompanhou-o ao longo de toda a narrativa, em uma contradição que, como menciona Halbwachs, aparentemente só ele percebe. Assim, o colaborador elaborou discursos de autodefesa, assumindo constantemente que

Anísio Teixeira foi um homem de grande cultura, um brasileiro [...] na legítima extensão da palavra, no sentido de que queria o bem para o Brasil, se ocupava da educação, se preocupava com a educação, e acompanhava a educação. (sujeito 01)

Em um dos mais ilustrativos excertos das entrevistas, esse mesmo sujeito colaborador delongou-se em descrever um episódio aparentemente banal e corriqueiro, mas que se recobre (e cobre a memória) de todo um simbolismo em relação ao fato descrito, ao lugar social ocupado pelo narrador, tanto no passado quanto no presente, e, sobretudo, às justificativas para a defesa do ponto de vista de seus pares e lugar social: 
Houve um movimento na Universidade [...], levaram um documento pedindo que as pessoas assinassem em solidariedade ao Anísio Teixeira. E esse documento não foi muito bem aceito. Alguns assinaram. Mas talvez a pessoa que encaminhou isso ficou meio decepcionada, porque muitas pessoas diziam 'Olha, aprecio muito o Dr. Anísio mas não quero assinar, porque eu sou católico', davam esta resposta. Foi uma coisa assim... davam esta resposta. E este documento, eu nunca soube se ele foi enviado, porque o número de assinaturas não era expressivo... Era uma professora da [...]. Eu sei que uma eu assisti no elevador, eu vi que trouxeram para assinar e disse: 'Não, eu não vou assinar, eu não conheço bem este caso... eu sou católica, tá muito complicado, eu não quero assinar'. Portanto você vê aí que ele não teve assim... Se fizermos isto aqui uma microexperiência, não foi assim tão grande a repercussão do lado dele (Anísio Teixeira), porque nossa comunidade é muito católica, né? (sujeito 01)

Como Anísio Teixeira fora atacado pela Igreja Católica no episódio em questão, havia a necessidade de configurar ataques também a Dom Vicente, como um subterfúgio da narrativa, ou uma maneira lícita de relatar que os eventuais ataques nominais ao educador baiano seriam fruto de uma retaliação ou reação a outros ataques sofridos, tal como fica evidente no seguinte relato:

Quem não era católico fazia troça da humildade dele [Dom Vicente], daquela maneira meio coloninho; ele falava como coloninho, uma vozinha de colono, fazia a voz do pastor no rádio. Então, quem não era católico dizia 'Ah, Dom Vicente é um [...]', mas não 'D. Vicente foi uma alma muito bonita, muito perfeita, muito iluminada'. (sujeito 01)
Nessa mesma perspectiva, o sentimento de desconforto e a necessidade constante de justificativa aos atos de Dom Vicente conduziram os sujeitos colaboradores a fazerem constantes intromissões na condução da pesquisa, sugerindo conclusões e novos focos de investigação, tal como na observação "eu acho que tu poderias explorar bem essa questão, do pós-incidente com Dom Vicente Scherer e Anísio Teixeira" (sujeito 01), precedida e reforçada pela seguinte narrativa:

agora tu que podes estudar bem a personalidade dele [Anísio Teixeira], tu poderias ver se de fato ele teve uma tendência mais pronunciada. Tu tens bons textos para estudá-lo? (sujeito 01)

Outro sujeito reitera que o debate entre Dom Vicente e Anísio foi relevante, mas que há outros elementos que pontuam o cenário, os quais, estes sim, mereceriam um estudo científico:

que vocês lá em [...] têm também... então, o ensino católico através dos pensionatos [...] os pensionatos fizeram um trabalho fabuloso e ainda não se escreveu esta história [...] e toda essa gente, porque havia poucos colégios. (sujeito 03 )

Habita esse espaço um gosto estranho de desconforto de quem confronta o passado com os referenciais e a relativização do presente. No calor da ocasião, Anísio Teixeira representava o perigo a ser combatido. Após quarenta anos, o perigo não mais existe e o combate travado parece tão fora de propósito que a justificativa faz-se forçosa, restando por deixar a memória em uma situação delicada: como narrar uma contenda que foi tão belicosa e passional utilizando o olhar e os referenciais do presente?

$\mathrm{Na}$ tentativa de deixar claro que o debate localizou-se em princípios dignos e justos, suas causas são apresentadas a partir de ataques aos valores humanos essenciais, como no relato que segue: 
A igreja e algumas associações católicas que trabalhavam em favor da educação naturalmente combateram, porque não se podia tolerar realizar uma educação eliminando os valores essenciais da pessoa. Era mais ou menos em torno disso que se armaram grupos, associações. (sujeito 02)

Nessa narrativa, há uma hipótese que a sustenta: a defesa intransigente dos valores da pessoa, identificados como valores católicos e sustentados por meio da educação. Tal defesa constituiu-se em álibi suficientemente forte para qualquer fala de Dom Vicente, pois

ele [Dom Vicente], como era naturalmente o líder católico, líder máximo, e as escolas católicas sendo mais ou menos visadas, atingidas direta ou indiretamente, ele se sentiu no dever de defender, isto é uma coisa natural. (sujeito 01)

Entretanto, se o argumento aparentemente irrefutável da defesa dos valores da pessoa falhava, os sujeitos colaboradores também se mostravam francamente favoráveis a desconfigurar o debate e a colocá-lo em proporção menor, com certo desdém. Isso ocorreu quando um dos sujeitos foi indagado sobre suas manifestações públicas contra Anísio Teixeira, ao que respondeu prontamente que não apenas ele, mas inúmeras pessoas haviam erigido manifestações públicas contra Anísio, pois o evento suscitou "um movimento que aqui fizemos também, nos opondo àquilo que eles queriam fazer; aliás, foi um movimento nacional" (sujeito 02). 0 mesmo desdém irrompe em outro sujeito colaborador quando este negocia argumentos, minimizando o fato de Anísio Teixeira ter sido católico (sujeito 03).

$\mathrm{Na}$ mesma direção, um colaborador menciona uma importante figura da educação nacional. Interpelado, durante o relato, sobre o fato de a pessoa citada ser um amigo público de Anísio, o sujeito reitera que se tratava de um grande católico, um católico sério, formado pelos jesuitas, uma pessoa belíssima, mas ele não foi muito nas 'águas' do Anísio, ele fez as pesquisas, mas, claro, ele fazia a 'driblada' dele, né? (sujeito 03)

Por seu turno, o sujeito narrador que se manteve fiel à memória e aos princípios de Anísio Teixeira deixou transparecer certo tom ressentido e indignado diante dos desdobramentos do caso e de quão nefastas foram a presença e a influência da Igreja Católica sobre o assunto.

Ainda inconformado com os substantivos pejorativos imputados ao educador baiano, o sujeito colaborador lembrava em tom irônico: "Anísio Teixeira era visto como um comunista, gente que espetava criança e assava em braseiro" (sujeito 04). Esse mesmo entrevistado teve uma lucidez rara em relação ao pano de fundo da contenda: não se tratava de uma mera discussão religiosa ou educacional, mas de dois projetos distintos de sociedade, claramente exemplificados em seu relato:

E tinham medo dessa balela do comunismo. Então, pensar na solidariedade humana, pensar em dar educação para todo o povo era comunismo, era 'ensinar esta gente para nos derrubar'. Agora mudou o pensamento geral daquela época para hoje. (sujeito 04)

Nominar Anísio e chamá-lo particularmente ao debate tratou-se, na visão do sujeito em questão, de uma estratégia para escamotear as reais bases de discussão da contenda; dois projetos distintos de sociedade, ou seja:

Dom Vicente era muito contra todo e qualquer projeto do Ministério devido ao Prof. Anísio, que eles intitulavam de comunista, só porque ele tinha um pensamento mais avançado, mais desenvolvido, defendendo a educação como um direito de todos, como uma obrigação do poder público. (sujeito 04) 
Pelo lugar social ocupado diante dos fatos narrados, esse sujeito colaborador tinha consciência do linchamento ideológico sofrido por Anísio Teixeira. Relatou ele, em tom indignado:

Filho de rico quer ir fazer uma universidade na França, perfeitamente vai com o dinheiro dele. Agora, esse rico tem que contribuir para que o filho do operário possa chegar à faculdade pública, para manter a faculdade pública [...], tem que pagar um tributo. (sujeito 04)

Com sua indignação referendada pela pergunta insistente "Estou certo?!”, ele traçava estratégias e elementos de convencimento sobre sua posição em relação aos fatos relatados. Por meio de argumentos, tentava ganhar a simpatia de eventuais interlocutores para a defesa do projeto de financiamento da escola pública, como se ainda houvesse algo a ser feito diante dos fatos. Além disso, buscava convencer, seduzir com seus argumentos, mostrando o quanto uma posição era sectária e sem fundamento social, enquanto a outra representava um avanço para a democracia e para o país.

É importante ponderar que, em face da posição do sujeito colaborador diante do episódio narrado, o texto pode ser direcionado para um ou outro termo. Nos excertos recolhidos e aqui utilizados com fins meramente ilustrativos, seria relativamente fácil conduzir a narrativa tanto para a defesa intransigente do discurso pastoral de Dom Vicente Scherer, quanto para a defesa dos argumentos anisianos sobre o financiamento e as políticas compensatórias em relação à educação.

Entretanto, pela parcialidade e posição dos sujeitos colaboradores, os projetos educacionais que sustentavam o debate ideológico são escamoteados e não ficam suficientemente claros, assim como não se cogitam as implicações da vitória de um ou de outro lado para os rumos da educação nacional.

\section{Para concluir}

[...] não me permiti e não me podia permitir

[...] face a face com a magnitude do assunto, senão simples esboço ou tentativa

de ensaio.

Anísio Teixeira

A epígrafe anisiana acima traduz, com precisão cirúrgica, o sentimento derradeiro diante da intenção inicial deste artigo: não é possível, em razão da magnitude e das incontáveis implicações do tema, nada além de um simples esboço.

Todavia, trata-se de um esboço focado: a intencionalidade deste texto não recaiu, em momento algum, sobre uma discussão de ordem epistemológica acerca do estatuto da história oral, tampouco de seus elementos metodológicos, até porque existem bibliografias consagradas sobre tais abordagens. Antes, o texto propôs-se a encaminhar argumentos e reflexões sobre a condição do sujeito que se dispõe a partilhar sua memória por meio da narrativa, em um processo de pesquisa no campo da educação, principalmente da história da educação.

Não se trata de recuperar o episódio de origem da pesquisa ou seus desdobramentos, mas os traços de pesquisa com fontes orais, os quais, como evoca o título do artigo, são circunstanciados a percursos e advindos de sujeitos colaboradores que, nessa posição, são fontes de pesquisa e assumem-se, sobretudo pela consciência de seu papel, tanto na narrativa, quanto nos eventos narrados.

Fazer o resgate dos fatos por meio da história oral permitiu trazer vida para dentro da narrativa, na tentativa de mostrar como um episódio inquietante é capaz de manter aquecida a memória, deixando-a aguerrida e posicionada pela retomada dos fatos para o registro da pesquisa.

Enquanto existe vida, existe lembrança. E esta se estrutura em uma moldura composta por tantos e tão variados materiais (sentimentos, sentidos, lugares sociais, projeções, esquecimentos etc.), que arrestar a lembrança e fixá-la em 
um único momento a partir do quadro estático da escrita é ir de encontro ao princípio cambiante da vida. As lembranças são tão fluidas quanto o próprio sentido que assumem ao serem narradas. Apreendê-las é sempre uma tarefa de referência: naquele momento e sob aquelas condições, a narrativa aportou aquelas nuanças da memória; momentos depois, para outro interlocutor, em outro contexto, a narrativa seria outra.
Reconstruir a memória daquele período também significou revigorar caricaturas, contradições e conflitos presentes nas diversas interpretações particulares dos sujeitos colaboradores, pois mesmo o relato histórico narrado para a constituição do texto não perdeu seu estatuto de apreensão íntima e social, uma construção/representação da classe ou do grupo ao qual cada sujeito acreditava pertencer.

\section{Referências}

ALBERTI, Verena. Ouvir contar: textos em história oral. Rio de Janeiro: Editora da FGV, 2004. 194p.

BENJAMIN, Walter. A imagem de Proust. In: Obras escolhidas I: magia e técnica, arte e política. São Paulo: Brasiliense, 1985. p. 36-49.

DELGADO, Lucília de Almeida Neves. História oral: memória, tempo, identidades. Belo Horizonte: Autêntica, 2006. 135p.

ESQUINSANI, Rosimar Serena Siqueira. Educação e ideologia: o caso Anísio Teixeira. Passo Fundo: Editora da Universidade de Passo Fundo, 2002. 155p.

FERREIRA, Marieta de Morais; AMADO, Janaína (Orgs.). Uso e abuso da história oral. 4. ed. Rio de Janeiro: Fundação Getúlio Vargas, 2001. 277p.

HALBWACHS, Maurice. A memória coletiva. São Paulo: Centauro, 2004. 197p.

MEIHY, José Carlos Sebe Bom. Manual de história oral. 5. ed. São Paulo: Loyola, 2005. 291 p.

MEIHY, José Carlos Sebe Bom; HOLANDA, Fabíola. História oral: como fazer, como pensar. São Paulo: Contexto, 2007. 175 p.

MONTENEGRO, Antônio. História, metodologia, memória. São Paulo: Contexto, 2010. 192p.

SCHERER, Vicente. Memorial dos bispos gaúchos ao Presidente da República sobre a Escola Pública Única. Vozes, Petrópolis, v. 52, p. 362-364, maio 1958.

TEIXEIRA, Anísio. Bases da teoria lógica de Dewey. Revista Brasileira de Estudos Pedagógicos, Rio de Janeiro, v. 23, n. 57 , p. 3-27, jan./mar. 1955.

THOMPSON, Paul. História oral: a voz do passado. Rio de Janeiro: Paz e Terra, 1992. 388 p.

Recebido em: 04.06.2011

Aprovado em: 08.11.2011

Rosimar Serena Siqueira Esquinsani é professora e pesquisadora do Programa de Pós-Graduação em Educação da Universidade de Passo Fundo (UPF). 